\title{
Multi-century variability in the Pacific North American circulation pattern reconstructed from tree rings
}

\author{
Valerie Trouet $\cdot$ Alan H. Taylor
}

Received: 17 February 2009/ Accepted: 2 June 2009/Published online: 16 June 2009

(C) Springer-Verlag 2009

\begin{abstract}
We here present a reconstruction (1725-1999) of the winter Pacific North American (PNA) pattern based on three winter climate sensitive tree ring records from the western USA. Positive PNA phases in our record are associated with warm phases of ENSO and PDO and the reorganization of the PNA pattern towards a positive mode is strongest when ENSO and PDO are in phase. Regime shifts in our PNA record correspond to climatic shifts in other proxies of Pacific climate variability, including two well-documented shifts in the instrumental period (1976 and 1923). The correspondence breaks down in the early 19 th century, when our record shows a prolonged period of positive PNA, with a peak in $1800-1820$. This period corresponds to a period of low solar activity (Dalton Minimum), suggesting a 'positive PNA like' response to decreased solar irradiance. The distinct 30-year periodicity that dominates the PNA reconstruction in the 18th century and again from 1875 onwards is disrupted during this period.
\end{abstract}

Keywords Pacific North American · PNA - PDO . ENSO $\cdot$ Reconstruction $\cdot$ Tree ring

\section{Trouet $(\bowtie)$}

Swiss Federal Research Institute WSL, Zürcherstrasse 111, Birmensdorf, Switzerland

e-mail: trouet@wsl.ch

\author{
A. H. Taylor \\ Department of Geography, Earth and Environmental Systems \\ Institute, The Pennsylvania State University, 302 Walker \\ Building, University Park, PA 16807, USA \\ e-mail: aht1@psu.edu
}

\section{Introduction}

The Pacific/North American (PNA) pattern is a dominant mode of atmospheric circulation over North America that strongly influences interannual climatic variability (Barnston and Livezey 1987; Wallace and Gutzler 1981). The PNA is most strongly expressed in the winter season as a distinct configuration in the mid-tropospheric geopotential height field over North America and the North Pacific (Fig. 1a). Enhanced ridges over the North American west coast and near Hawaii, accompanied by a deepening of the Aleutian Low in the North Pacific, and development of deep troughs over the southeastern United States (USA) are characteristic of a positive mode PNA (PPNA). A reverse PNA mode (RPNA) is associated with characteristic negative geopotential height anomalies over western North America and positive anomalies over the North Pacific and the southeast USA.

The amplified ridge over western North America under winter PPNA conditions advects maritime air from the south into the region and deflects moisture-bearing cyclonic systems from the Pacific northward, creating primarily meridional flow over the North American continent (Leathers et al. 1991). Subsidence under the ridge and the northward deflection of Pacific storm tracks results in above normal temperatures and below normal precipitation over the northwestern USA (Fig. 1b, c; Sheridan 2003). Wetter and cooler conditions are generated by the deep trough and the southward displacement of the polar front jet stream over the southeastern USA (Fig. 1b, c). During the RPNA, the mean position of the polar front jet stream over the eastern USA is displaced further north than average promoting more frequent intrusions of maritime tropical air from the Gulf of Mexico and increasing precipitation (Archambault 

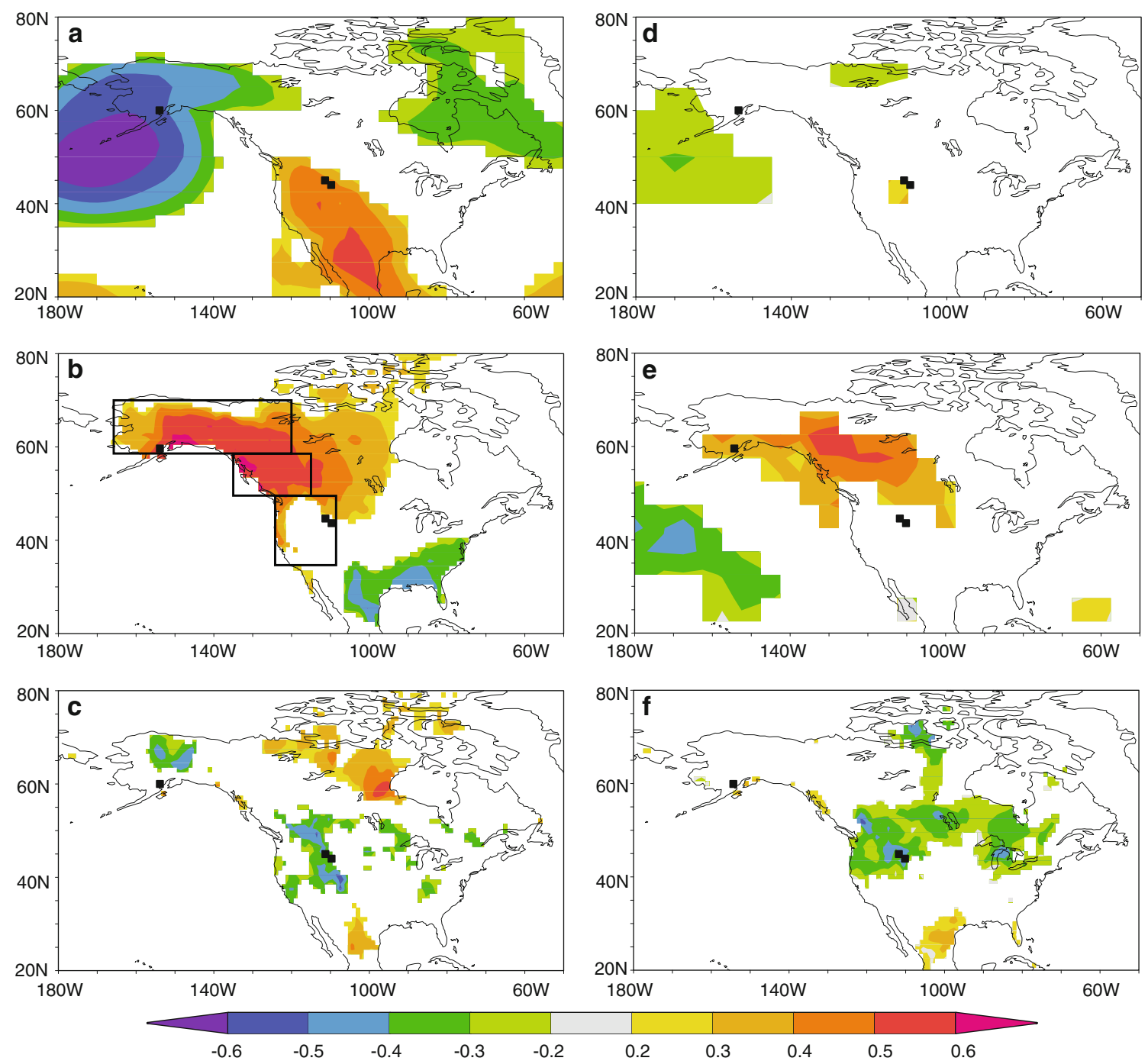

Fig. 1 Correlation maps of winter (December, January) instrumental $(\mathbf{a}-\mathbf{c})$ and reconstructed $(\mathbf{d}-\mathbf{f})$ PNA index and winter SLP fields (a NCAR/NCEP, 1950-2007; d Trenberth and Paolino 1980, 18991999), winter surface temperature fields (b CRUTS2.1, Mitchell et al. 2004, 1950-2001; e HADCRUT3, 1850-1999), and winter precipitation fields (c CRUTS2.1, 1950-2001; f CRUTS2.1, 1901-1999).

et al. 2008; Henderson and Robinson 1994) and temperature over the region. Nearly zonal westerly flow off the North Pacific during RPNA directs Pacific storms and polar air intrusions towards the northwestern USA. Higher winter precipitation and lower temperatures are characteristic of this region during RPNA (Leathers et al. 1991).

PPNA phases produce below average snow accumulation rates in western North America as a result of warm temperatures and decreased precipitation, whereas RPNA phases generate positive snow anomalies (Cayan 1996; Hamlet et al. 2005; Hsieh and Tang 2001; McCabe 1994; Redmond and Koch 1991; Romolo et al. 2006a, b). Up to
Black squares on the maps indicate the locations of the three tree ring sites (NFR, MTE, and FT). Boxes in (b) indicate the regions where tree ring chronologies for the stepwise regression model were selected. Maps were generated using the KNMI explorer (Van Oldenborgh and Burgers 2005; http://climexp.knmi.nl)

$39 \%$ of snow accumulation variability at elevations above $1,000 \mathrm{~m}$ in the western USA can be explained by the PNA pattern (Jin et al. 2006). The increased rain to snow ratio during PPNA winters contributes to below-average glacier mass balances in western North America (McCabe and Fountain 1995). Lake-ice and river-ice break-ups also occur earlier after PPNA winters (Bonsal et al. 2006; Magnuson et al. 2000) and a 265-year reconstruction of Great Lake levels is correlated with the PNA teleconnection pattern (Wiles et al. 2009). Additionally, streamflow variability in snowmelt-dominated rivers in western North America (Coulibaly and Burn 2004; Gobena and Gan 2006; Moore and McKendry 1996) and in the Midwest (Coleman 
and Rogers 2003; Rogers and Coleman 2003) is influenced by the PNA pattern.

Finally, earlier spring snowmelt in PPNA years can cause increased forest wildfire activity (Westerling et al. 2006) and increased fire risk and extent in western USA forests have been linked to PPNA winters (Trouet et al. 2006, 2009b).

The expression of the PNA pattern on climate is evident over a range of time-scales from weeks to decades (Blackmon et al. 1984). For example, the frequency and formation of blocking events over the North Pacific basin, with a life-cycle of several days up to weeks, is enhanced during RPNA and suppressed during PPNA (Croci-Maspoli et al. 2007; Renwick and Wallace 1996). On seasonal timescales, the PNA reaches maximum strength in winter when the subtropical jet stream and cyclonic storms are most intense (Barnston and Livezey 1987; Davis and Benkovic 1994), but the PNA is a major feature of hemispheric-scale circulation in all seasons except summer (Coleman and Rogers 2007). There is also coherence in the frequency domain of the PNA at interannual time scales. A spectral analysis of the PNA index (calculated as a combination of standardized $500 \mathrm{hPa}$ geopotential height values in four centers of action; Wallace and Gutzler 1981) for the period 1947-1987 revealed a peak at 36-45 months and an overall quasi-periodic character to the PNA pattern (Leathers and Palecki 1992). PNA also exhibits variability over multidecadal time-scales (Overland et al. 1999; Yarnal and Leathers 1988): the PNA was in a predominantly negative (reverse) phase from 1950 to 1975 , followed by a positive phase that lasted until the late 1980s. The shift in Pacific climate in 1976 is well documented (Deser et al. 2004; Graham 1994; Mantua et al. 1997; Trenberth and Hurrell 1994) but long-term patterns of variability and shifts in the PNA are poorly known and not well understood.

Variability in the PNA pattern is also influenced by large scale ocean-atmosphere circulation patterns. The El Niño southern oscillation (ENSO) is a high frequency (i.e. 25 years) coupled ocean-atmosphere process in the eastern and central equatorial Pacific Ocean that is a primary driver of North American interannual climate variability (Diaz and Markgraf 2000). Mid-tropospheric geopotential height anomalies associated with the PPNA mode tend to be more frequent during warm (El Niño) than cool (La Niña) ENSO phases (Horel and Wallace 1981; Renwick and Wallace 1996; Yarnal and Diaz 1986). A similar phase association has been identified with the Pacific decadal oscillation (PDO; Mantua et al. 1997), an interdecadal variation in north Pacific sea surface temperatures (SST): the PPNA mode is more frequent during a warm than cool PDO (Hsieh and Tang 2001). Moreover, PDO modulates climatic variation associated with ENSO (Gershunov and Barnett 1998) and this interaction is likely expressed in the long-term variability of the PNA. A coupled ocean-atmosphere model simulation run for a 1,000-year period suggests that a PNA-like climate response over North America is enhanced when ENSO and the PDO are in phase (Yu and Zwiers 2007). Finally, low frequency Atlantic multidecadal oscillation-like (AMO; Kerr 2000) fluctuations (Zhang and Delworth 2007) have been found to contribute to preferred PNA phases. However, the number of the PDO and AMO cycles in the observational record (1950-present) is limited and the conclusions that low-frequency SST forcings (i.e. PDO, AMO) contribute to PNA variability are preliminary (Yu et al. 2007).

Instrumental records of the PNA are too short (post 1948) to evaluate the long-term dynamics and variability of the PNA. Here we develop a multi-century proxy record of PNA variability from tree rings to (1) analyze multidecadal variability and spatio-temporal teleconnection patterns of PNA, (2) identify the sensitivity of the PNA to SST forcings (ENSO, PDO, AMO), and (3) identify temporal shifts in the PNA and their correspondence with temporal shifts in other proxy records of Pacific climate.

\section{Materials and methods}

\subsection{Tree ring data and model development}

We developed our reconstruction of winter PNA by selecting a subset of 12 standardized tree ring width chronologies from the International Tree Ring Data Bank (ITRDB; http://www.ncdc.noaa.gov/paleo/treering.html) that were (1) located within the core region of PNA influence on winter climate (Fig. 1b) and (2) spanned at least the period 1700-1999. The choice of this time period allowed us to reconstruct PNA back to at least 1700, while keeping the calibration period as long as possible (19511999).

All chronologies were developed according to standard dendrochronological methods and growth trends were removed from individual tree ring width series using negative exponential or linear regression models (Cook and Kairiukstis 1990; Fritts 1976). To preserve low-frequency climatic signals in the tree ring series, no autoregressive modelling for the removal of low-order autocorrelation was performed.

The choice of individual tree ring series to include in the final model was determined by entering the 12 tree ring chronologies as predictor variables of the winter PNA index (PNAI) in a stepwise linear regression process. This process excludes chronologies with high serial correlation and/or those insensitive to variation in winter PNAI over the instrumental period (1950-1999). Three tree ring series were selected by the stepwise regression process and the 
Table 1 Location, species, and statistical description of tree ring chronologies selected by stepwise linear regression as predictors for winter PNAI

\begin{tabular}{llll}
\hline & North Fork Ridge & Mount Everts & Fish Trap \\
\hline Abbreviation & NFR & MTE & FT \\
ITRDB code & MT111 & WY027 & AK086 \\
Location & $45^{\circ} \mathrm{N} 111^{\circ} \mathrm{W}$ & $44^{\circ} \mathrm{N} 110^{\circ} \mathrm{W}$ & $60^{\circ} \mathrm{N} 154^{\circ} \mathrm{W}$ \\
Elevation (m) & 2,500 & 2,179 & 550 \\
Tree species & Pinus flexilis & Pseudotsuga menziesii & Picea glauca \\
Number of cores & 65 & 65 & 42 \\
Inter-series correlation & 0.553 & 0.756 & 0.607 \\
Chronology length & $540-2000$ & $1285-1999$ & $1691-2003$ \\
Correlation with PNAI (1950-1999) & 0.522 & -0.471 & -0.38 \\
Reference & King JC (2000) & Graumlich et al. (2003) & Driscoll et al. (2005) \\
\hline
\end{tabular}

combination of these series explained $49 \%$ of the variance in winter PNAI (Table 1).

\subsection{Model calibration and verification}

We calibrated and verified the regression model for winter PNAI using a leave-one-out calibration-verification scheme (Michaelsen 1987, Woodhouse and Lukas 2006). This method calibrates a model using all years in the PNA record but one; the missing value is then estimated. This is iterated for all predictor variables for each year of the calibration period. We evaluated the predictive skills of the model using both a reduction of error (RE) statistic and a sign test (Cook et al. 1994; Fritts 1976). RE compares regression model estimates to estimates based on the calibration period mean, and positive RE values indicate predictive skill. A sign test compares the frequency of agreements and disagreements in sign from the mean from observed and reconstructed values.

Uncertainty in our tree ring reconstruction of winter PNAI arises from unexplained variance in the regression model (calibration error) and the decreasing number of tree ring series back through time (chronology error; Esper et al. 2007). We estimated the calibration error as two standard error (SE) 95\% confidence intervals (CI) for the regression model with three annual predictor variables for the full calibration period 1949-1999. We used ARSTAN software (Cook 1985) to estimate the chronology error by bootstrapping (Briffa et al. 1992). Standardized tree ring measurements for every year were sampled with replacement 1,000 times and arithmetic mean were calculated. Two-tailed $95 \%$ CI were estimated based on the distribution of the bootstrapped mean. The upper and lower limits of the CI for each chronology were then entered in the regression model. The overall error for the PNAI
Table 2 Stepwise linear regression model calibration and verification statistics

\begin{tabular}{ll}
\hline$R_{\mathrm{a}, \text { calibration }}^{2}$ & 0.49 \\
$R_{\mathrm{a}, \text { verification }}$ & 0.47 \\
Reduction in error (RE) & 0.52 \\
Sign test & $34 / 50^{*}$ \\
\hline
\end{tabular}

$* P<0.05$

reconstruction was then estimated as the square root of the summed and squared calibration and chronology error terms.

Our model passed all verification tests: $47 \%$ of the variance in winter PNAI was explained by the model in the verification procedure (Table 2). The results of the RE test were also positive and the sign test was significant $(P<0.05)$, indicating the stability of the tree-ring based regression model.

\subsection{Climatic data}

We used the average December-January PNAI from the Climate Prediction Center (http://www.cpc.ncep.noaa.gov) for the period 1950-2007 as our measure of interannual variability in the PNA. The PNAI is calculated by applying a rotated principal component analysis to monthly standardized $500 \mathrm{hPa}$ height anomalies (Barnston and Livezey 1987). February was excluded from our index because the correlation of PNA with western North American precipitation is considerably lower in February than in December and January (Leathers et al. 1991).

For the climate-growth analysis of the three tree ring records contributing to our regression model, we calculated seasonal mean (fall, September-November; winter, December-February; spring, March-May; summer, 
June-July) from monthly precipitation and temperature data for the appropriate $0.5^{\circ}$ gridpoints from the CRU TS2.1 data set (1901-2001; Mitchell et al. 2004).

\subsection{PNA time series analysis}

Periodicity in the PNAI reconstruction was identified using a multi-taper method spectral analysis (Jenkins and Watts 1968). A wavelet analysis was also performed (Torrence and Compo 1998) on the full reconstruction to determine if low-frequency behaviour of the PNA was stationary over time. Significance was tested (95\% CI) against a red-noise background.

A composite analysis of extreme years was used to identify interactions between PNA and ENSO, PDO, and AMO. We identified the 25 highest and lowest years of ENSO, PDO, and AMO, and then averaged winter PNAI for these sets of extreme years and compared the mean using a Student's $t$ test. We used the winter season (December-February) values of Niño3.4 (ENSO) (18561999; Kaplan et al. 1998), PDO (1900-1999; Mantua et al. 1997), and AMO (derived from HadSST2; 1850-1999; Van Oldenborgh and Burgers 2005) for the composite analysis.

We identified climate shifts in our PNAI reconstruction using an intervention detection algorithm. The algorithm tests the difference between PNAI in the first and second half of 30-year moving windows with a twosample $t$ test. Most shifts had more than one consecutive year with a significant $(P<0.05) t$ value and a shift year was defined as the year within this period with the highest $t$ value (Fig. 5). We then identified the similarity in coincidence of PNAI shifts to other decadal records of Pacific climate variability (i.e. to Biondi et al. 2001; D'Arrigo et al. 2005; Gedalof and Smith 2001; MacDonald and Case 2005; Wilson et al. 2007) and solar activity (Crowley 2000) using the Jaccard index (GreigSmith 1983).

\section{Results}

\subsection{Growth climate relations}

The three tree ring series in the final model respond to different PNA influences on winter climate. Trees at site FT are in a region where variation in PNA influences mainly winter temperature (Fig. 1b; Table 1) and radial growth of Picea glauca on this site was sensitive $(P<0.05)$ to variation in both winter and spring temperature (Fig. 2). In the northern Rocky Mountains, where the climate is characterized by generally wet winters and dry summers, winter PNA has a strong influence on winter precipitation (Fig. 1c) and (NFR) and Pseudotsuga menziesii (MTE) radial growth was sensitive to variations in precipitation in fall, winter, and spring, depending on species and site. Summer and fall temperatures had a strong negative influence on tree growth at MTE.

\subsection{Winter PNAI reconstruction}

We reconstructed winter PNAI for the period 1691-1999 using the selected tree ring width series and the regression model:

$$
\begin{aligned}
\mathrm{PNAI}= & -1.67+6.02 \times \mathrm{NFR}-2.27 \times \mathrm{MTE} \\
& -2.6 \times \mathrm{FT}
\end{aligned}
$$

As with most tree ring reconstructions of climate, our model gives conservative estimates of observed values and the range of reconstructed PNAI values is narrower than the observed values over the same period (Fig. 3a). The loss of range is more pronounced for positive than negative values. The reconstructed extreme positive PNAI value is $70 \%$ of the maximum observed PNAI (2.02 vs. 2.87), whereas the reconstructed extreme minimum PNAI value is $93 \%$ of the observed value $(-3.17$ vs. -3.39$)$. The greater skill in prediction for extreme low than extreme high values is also reflected in the contingency analysis (Table 3): nine of ten observed low or very low PNAI
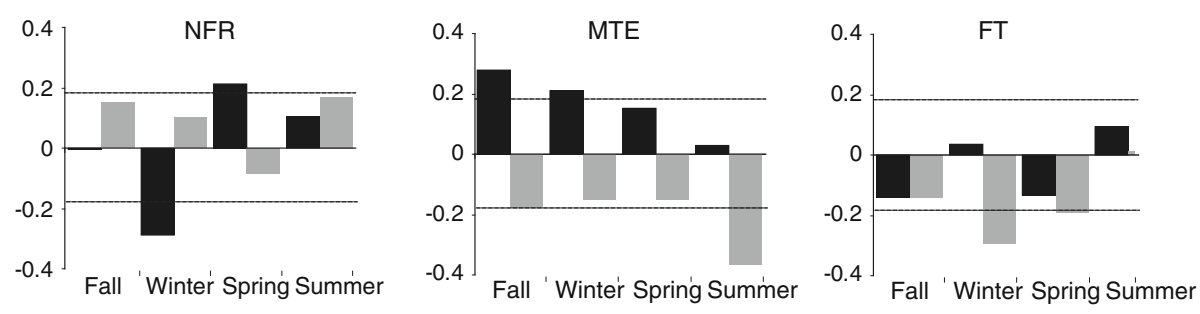

Precipitation Temperature

Fig. 2 Pearson correlation coefficients between tree ring width and seasonal precipitation and temperature for the three tree ring series used to reconstruct winter PNAI. Seasonal climate data were derived for the appropriate $0.5^{\circ}$ gridpoints from the CRU TS2.1 data set (1901-2001; Mitchell et al. 2004). The dashed lines are critical values for statistical significance $(n=100 ; P=0.05)$ 


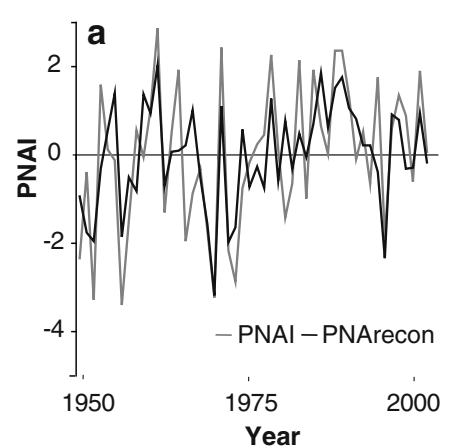

Fig. 3 a Reconstructed versus observed values for winter PNAI for the calibration period (1950-1999) and b tree ring reconstruction of winter PNAI for the period 1691-1999. We smoothed the reconstruction in b with a 20-year spline (heavy line) to represent multi-

Table 3 Contingency table of observed and reconstructed winter PNAI values (1950-1999)

\begin{tabular}{llllll}
\hline \multirow{2}{*}{ Reconstructed PNAI } & \multicolumn{5}{l}{ Observed PNAI } \\
\cline { 2 - 6 } & Very low & Low & Moderate & High & Very high \\
\hline Very low & 8 & 1 & 0 & 1 & 0 \\
Low & 1 & 3 & 3 & 2 & 1 \\
Moderate & 1 & 3 & 2 & 2 & 2 \\
High & 0 & 2 & 3 & 3 & 2 \\
Very high & 0 & 1 & 2 & 2 & 5 \\
\hline
\end{tabular}

Years were ranked and divided into five equal 10-year classes. The class of the reconstructed PNAI for each year was then compared to the class for the observed PNAI

values were in the same classes as reconstructed values. In contrast, only seven of ten (very) high observed values fell in the same class as reconstructed values.

The PNAI reconstruction extends back to 1691, but estimated uncertainty in the earliest part of the record (1691-1725) was high due to the decreasing number of tree ring series in the reconstruction (Fig. 3). Consequently, we use only the period 1725-1999 in the subsequent analyses.

Over the last three centuries, the PNA has been mainly in a negative phase (Fig. 3). The major exception was a prolonged period of positive values from ca. 1780 to 1830 , with a peak from 1800 to 1820 . Winter PNA has also been in a more positive phase over the most recent, instrumental period (from 1950 onwards). The range of values found for the instrumental period, for the annual series as well as for the smoothed (20 years) series, fall within the range of the full reconstruction. The negative PNA phase in the early 1950s in the instrumental record is near the end of a 13year long negative phase (1941-1953), that corresponds to a wet and cool period in the American West, and is preceded in length only once by a negative phase in the early 1700s (1731-1743).

\subsection{Winter PNA teleconnections}

Sea level pressure (SLP) patterns for reconstructed and observed positive and negative PNA winters (Fig. 1d) resemble patterns over the instrumental period (Fig. 1a). The correlation map for gridded SLP fields (1899-1999; Trenberth and Paolino 1980) shows a deeper (higher) Aleutian Low for positive (negative) PNA winters. The extensive amplified ridge over western North America, characteristic of positive PNA winters in the instrumental period, is limited in extent for the reconstructed period. Our winter PNAI reconstruction is positively correlated with winter temperatures (1870-1999) over much of northwestern North America (Fig. 1e) and winter temperatures tend to be higher in positive and lower in negative PNAI winters, respectively. The correlation with SSTs over the North Pacific corresponds to the deepening (lifting) of the Aleutian Low during positive (negative) PNA phases.

The correlation patterns of the reconstructed and observed winter PNAI with winter precipitation were also similar (Fig. 1c, f): during positive (negative) PNA winters, predominantly dry (wet) conditions occur in the Pacific Northwest, the northern great plains, and the Great Lakes region. In the southwestern USA the correlation patterns were also similar but just the opposite. The negative correlation between PNAI and winter precipitation over large parts of Alaska for the instrumental record is not evident in the correlation map for the reconstructed PNAI.

\subsection{SST forcing and climatic shifts in winter PNA}

Modes of Pacific SST had a strong influence on winter PNA and winter PNAI values were higher when ENSO was most $(n=25)$ positive compared to when it was most $(n=25)$ negative $(t=2.02, \quad P<0.05$; Fig. 4$)$. 


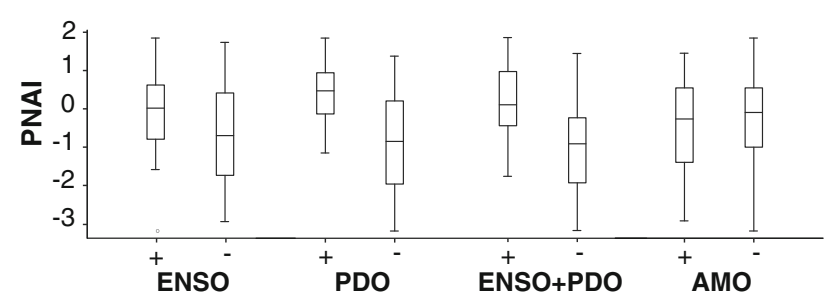

Fig. 4 Box and whiskers plots for reconstructed winter PNAI values during the 25 most positive and negative years of ENSO, PDO, and combined ENSO and PDO. The central line indicates the median, the boxes the interquartile range (IQR), and the whiskers the highest/ lowest values within 1.5 IQR from the end of the box

Differences in PNAI were even greater for the most positive versus most negative PDO years $(t=4.32, P<0.01)$ and when ENSO and PDO interference was constructive $(t=4.722, P<0.01)$. Values for winter PNAI can be positive under either extreme positive or negative ENSO and PDO conditions, but no extremely negative PNAI values (lower than -2 ) occurred during extremely positive ENSO or PDO phases (Fig. 4). No significant differences were found between PNAI values during positive and negative AMO phases $(t=0.171, P>0.05)$.

We identified 13 shifts in winter PNAI between 1725 and 1999 (Fig. 5), including two shifts in the instrumental record in $\sim 1976$ and $\sim 1923$. The shift in 1923 is less pronounced $(t=2.45 ; P<0.05)$ than the 1976 shift $(t=3.49 ; P<0.01)$. Various shifts in the 19th and 18th centuries, including the shifts of 1906, 1891, and 1764, were also evident in other records of Pacific decadal variability (taking a 3-year margin into account) and shift years in winter PNAI were up to $31 \%$ similar to shift years in these records (Table 4). The Jaccard similarity coefficients for winter PNAI fell within the range of coefficients for the
Fig. 5 Climatic shift years in the normalized (1725-1999) winter PNAI series, identified using a two-sample $t$-test between the first and second half of 30-year moving windows. Significance levels are indicated by full $(P<0.01)$ and dashed $(P<0.05)$ horizontal lines. Climatic shift years (vertical dashed lines) were defined as the years with highest absolute $t$-value. Years of climatic shifts identified in other proxy records of Pacific climate variability and solar activity (Crowley 2000) are also indicated. Filled symbols represent climatic shifts within a 3 year range from the shifts in winter PNAI

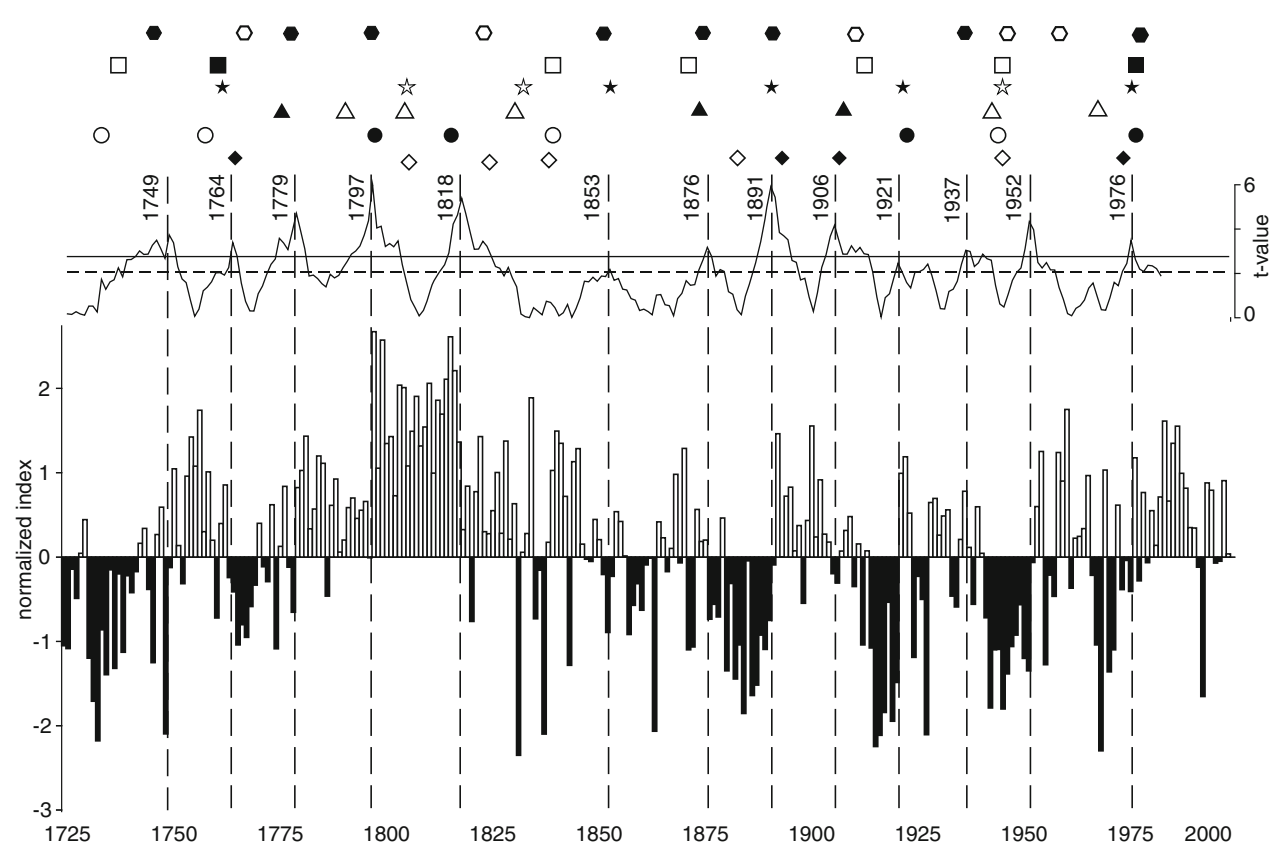

•Biondi et al. 2001 Gedalof and Smith 2001 AMacDonald and Case $2005 \star D ’ A r r i g o$ et al. 2005 Wilson et al. 2007@Crowley 2000

Table 4 Jaccard similarity index for climate shift dates in our winter PNAI reconstruction, in five proxy records of Pacific climate variability (Biondi et al. 2001; D'Arrigo et al. 2005; Gedalof and Smith 2001; MacDonald and Case 2005; Wilson et al. 2007), and in a proxy record of solar activity (Crowley 2000)

\begin{tabular}{lllllll}
\hline & PNAI & Biondi & Gedalof & MacDonald & D'Arrigo & Wilson \\
\hline PNAI & 1 & & & & & \\
Biondi & 0.22 & 1 & & & & \\
Gedalof & 0.31 & 0.31 & 1 & 1 & & 1 \\
MacDonald & 0.17 & 0.21 & 0.07 & 0.23 & 0.25 & 1 \\
D'Arrigo & 0.31 & 0.42 & 0.33 & 0.07 & 0.24 & 0.18 \\
Wilson & 0.11 & 0.33 & 0.5 & 0.17 & & 1 \\
Crowley & 0.44 & 0.16 & 0.17 & & & \\
\hline
\end{tabular}



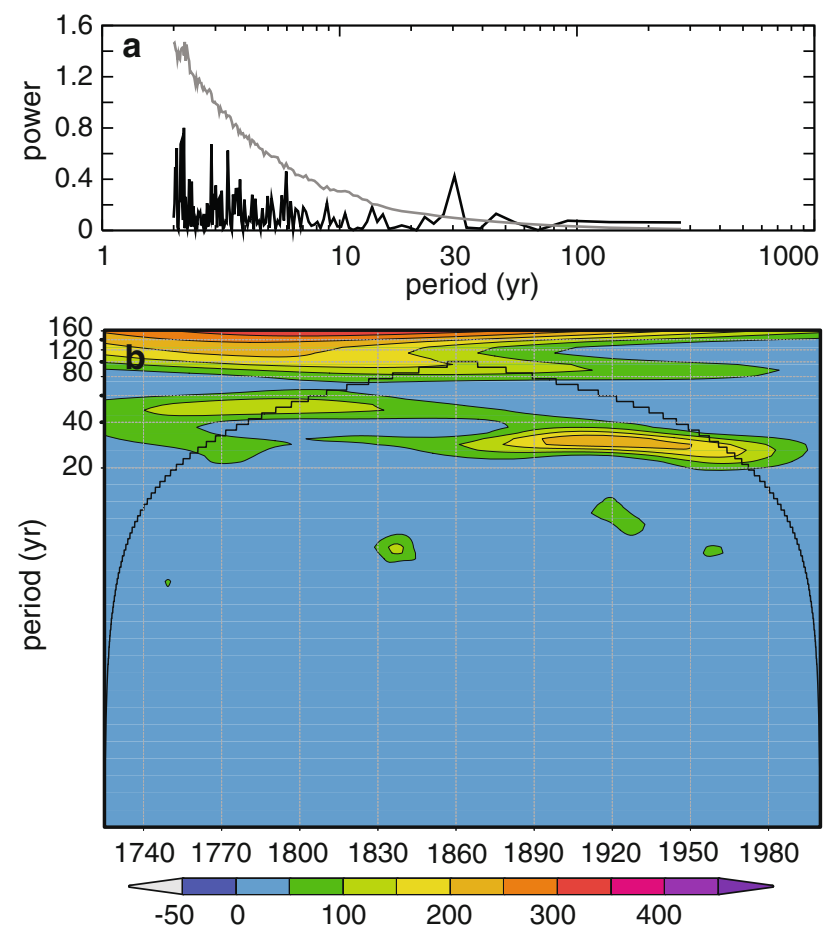

Fig. 6 Spectral (a) and wavelet (b) (Morlet 6; Torrence and Compo 1998) analysis for reconstructed winter PNAI for the period 17251999. The $95 \%$ confidence interval for peaks in the power spectrum is indicated by the grey line. The cone of influence in the wavelet analysis is indicated by the black line. Periods outside the cone are influenced by the boundaries of the time series and are unreliable

other records. The highest similarity coefficient $(0.44)$ was found for shift years in a record of solar activity (Crowley 2000).

There are two distinct periods in the record, 1749-1797 and 1876-1952, when intervals between climatic shifts typically last for 15 years. The frequency of 15 year intervals between shifts in winter PNAI is strongly reflected in its power spectrum, which shows a clear peak at a 30-year period (Fig. 6a), and maximum variability at this time-scale. The power spectrum peak at 30 years is confirmed by a wavelet analysis (Fig. 6b), which reveals that it is most strongly pronounced from 1870 onwards.

\section{Discussion}

This work represents the first tree-ring reconstruction of winter PNA which combines three tree ring records sensitive to winter climate in Montana, Wyoming, and Alaska, USA. It is interesting to note that the two sites in Montana and Wyoming, despite close proximity, induce an opposite sign in the regression model. NFR is located at a higher elevation where colder temperatures and high winter precipitation in the form of snow reduce tree growth. In years of abundant snowfall, the snowpack can persist into spring and early summer, thus shortening the growing season (Graumlich et al. 2003). On the other hand, tree growth at site MTE, which is at lower elevation in this semi-arid region, is enhanced by high winter precipitation. The Alaskan record we used in our regression model is derived from a winter-spring temperature sensitive sub-population at the FT site.

Our 275-year long reconstruction of interannual and interdecadal PNA variability allows us to investigate lowfrequency PNA dynamics, connections to other modes of Pacific climate variability, and responses to external forcings. Mid-tropospheric geopotential height anomalies associated with the PPNA mode in our record tend to occur more frequently during warm phases of ENSO and PDO confirming the results of studies that use only the instrumental record (Horel and Wallace 1981; Renwick and Wallace 1996; Yarnal and Diaz 1986). The reorganization of the PNA pattern towards its positive mode is strongest when ENSO and PDO are in phase: PDO exerts a modulating effect on mid-latitude climate variability induced by ENSO (Gershunov and Barnett 1998; Verdon and Franks 2006). Heating in the North Pacific and Tropical Pacific regions then vary in the same direction and provide anomalous atmospheric energy transports towards North America. This in turn can lead to the occurrence of stationary wave anomalies and a PNA-like wave anomaly pattern (Yu and Zwiers 2007; Yu et al. 2007). In contrast to Renwick and Wallace (1996) we find PNA variance to be slightly higher during cool PDO and ENSO phases compared to warm phases.

Regime shifts in our winter PNAI record co-occur with climatic shifts in various PDO proxies, including two well-documented shifts over the instrumental period (1976 and 1923; Deser et al. 2004; Graham 1994; Mantua et al. 1997; Trenberth and Hurrell 1994). Corresponding shift years are also found in a coral-based record of the interdecadal Pacific oscillation (Linsley et al. 2000; 1764, 1779, 1875, and 1979) and in a coral-based Indo-Pacific Ocean tropical index reconstruction (Deser et al. 2004; 1879, 1894, 1923, and 1976). Some of the climatic shifts that are well-synchronized between other records, however, are missing in our record. This is particularly the case for shifts in $\sim 1947$ and in the early 19th century ( $\sim 1840$, and $\sim 1805)$. Temporal changes in the amplitude and variability of all modes of Pacific climate variability (ENSO, PDO, and PNA) during the early 19th century are a probable cause for reduced correspondence between proxies during the latter period, but non-stationary climate-tree growth relationships cannot be excluded.

The early 1800 s were characterized by low solar irradiance (Dalton Minimum; ca. 1790-1830; Eddy 1977) and 
high volcanic activity. A number of proxy records indicate that SSTs in the North Pacific region (D’Arrigo et al. 1999) and air temperature in the Pacific Northwest (Wiles et al. 1996), in the Sierra Nevada (Graumlich 1993), and in the Canadian Rockies (Case and MacDonald 1995; Luckman et al. 1997) were unusually low during this period. Other studies have suggested an unusually cool PDO phase (D'Arrigo et al. 2001) and reduced PDO variability (Biondi et al. 2001; Gedalof et al. 2002), whereas reconstructed (D'Arrigo et al. 2005) and modelled (Mann et al. 2005) ENSO variability was enhanced. The 'ocean thermostat mechanism' (Clement et al. 1996), in which a cooling of the tropical Pacific Basin leads to a heating of the eastern tropical Pacific, can explain this 'El Niño-like' response to the decrease in radiative forcing during the Dalton Minimum (Mann et al. 2005).

Our PNA reconstruction reveals a long period (17801830) of positive winter PNAI during the Dalton Minimum, with a prominent peak between 1800 and 1820 (Fig. 3b). Also the Damon Minimum of solar irradiance (ca. 1890-1920) is associated with positive PNAI values. This 'PPNA-like' response to decreased solar irradiance can be explained by the combined effect of cold SSTs in the North Pacific region, associated with a deepening of the Aleutian Low, and a heating of the eastern tropical Pacific. A strong influence of solar variability on the PNA pattern is also suggested by the similarity in regime shift years between our PNAI record and a proxy record of solar activity (Crowley 2000): 8 out of 13 PNA shift years correspond to shifts in the solar record. The similarity of shifts in solar activity with the PNA is stronger than with any other record of Pacific decadal variability.

The strong link of winter PNAI to anomalously low solar irradiance during the early 1800 s caused a disruption of the distinct 30-year periodicity that dominates the PNAI reconstruction in the 18th century and again from 1875 onwards. The transition to an increased periodicity in the PNAI record around 1875 coincides with a strengthening of the teleconnection between the equatorial and the northern Pacific sectors (D'Arrigo et al. 2005), which is manifested in an increase in correlation between tropical and extratropical Pacific proxy records of climate (Biondi et al. 2001; Gedalof et al. 2002) suggesting an increased role of the tropics in driving 20th century Pacific climate variability.

The distinct positive PNAI peak in $1800-1820$ coincides with a negative peak in summer (July-August) North Atlantic oscillation (NAO) reconstructions (Linderholm et al. 2007; Luterbacher et al. 2002). An 'atmospheric bridge' that links the North Pacific and the North Atlantic regions (Lau et al. 2004) may explain the co-occurrence of these circulation extremes. The mechanism for the atmospheric bridge would be the eastward propagation of stationary Rossby wave trains from the North Pacific into the North Atlantic, triggering a seesaw in the intensities of the Icelandic and Aleutian lows (Honda and Nakamura 2001). The seesaw relationship has been identified on an interannual time scale in the 20th century instrumental record and there was limited evidence for low frequency multidecadal modulations (Honda et al. 2005). Our PNAI record suggests that the decadal-scale interactions linking Pacific and Atlantic climate were also operating in the 19th century.

Since the mid-1970s, the PNA has been in a predominantly positive mode caused by a shift towards a deeper Aleutian Low (Trenberth and Hurrell 1994) and resulting in drought conditions (Sheridan 2003) and increased fire risk (Trouet et al. 2006, 2009b) in the Pacific Northwest and California. This positive phase is not extraordinary in the context of the 275-year long record of winter PNA presented in this study. Our PNA reconstruction suggests an association with other synoptic circulation patterns in the equatorial and northern Pacific and a modulation by radiative forcing. The development of long reconstructions of synoptic-scale circulation patterns can contribute to a further understanding of these associations and their sensitivity to external forcings (Trouet et al. 2009a). Longer PNA reconstructions in particular can cover other-and more extreme-periods of solar activity fluctuations, such as the Maunder Minimum ( 1645-1715), and multiple replications of the 30-year PNA cycle. The development of long PNA reconstructions is therefore necessary to fully examine the sensitivity of PNA to external forcings and the persistence of its 30-year periodicity, two key concerns for assessing the potential impact of future climatic change on North America.

Acknowledgments This research was supported by a cooperative agreement with the USDA Forest Service, Pacific Southwest Research Station (04-JV-11272162-407) from funds provided by the USDI/ USDA Interagency Joint Fire Sciences Program and a George S. Deike Research Grant. We thank Jan Esper, David Frank, Bernd Haupt, and two anonymous reviewers for helpful suggestions.

\section{References}

Archambault HM, Bosart LF, Keyser D, Aiyyer AR (2008) Influence of large-scale flow regimes on cool-season precipitation in the northeastern United States. Mon Weather Rev 136:2945-2963

Barnston AG, Livezey RE (1987) Classification, seasonality and persistence of low-frequency atmospheric circulation patterns. Mon Weather Rev 115:1083-1126

Biondi F, Gershunov A, Cayan DR (2001) North Pacific decadal climate variability since 1661 . J Clim 14:5-10

Blackmon ML, Lee YH, Wallace JM, Hsu HH (1984) Time-variation of $500-\mathrm{Mb}$ height fluctuations with long, intermediate and shorttime scales as deduced from lag-correlation statistics. J Atmos Sci 41:981-991 
Bonsal BR, Prowse TD, Duguay CR, Lacroix MP (2006) Impacts of large-scale teleconnections on freshwater-ice break/freeze-up dates over Canada. J Hydrol 330:340-353

Briffa KR, Jones PD, Bartholin TS, Eckstein D, Schweingruber FH, Karlen W, Zetterberg P, Eronen M (1992) Fennoscandian summers from AD-500 - temperature-changes on short and long timescales. Clim Dyn 7:111-119

Case RJ, MacDonald GM (1995) A dendroclimatic reconstruction of annual precipitation on the western Canadian prairies since A.D. (1505) from Pinus flexilis James. Quat Res 44:267-275

Cayan DR (1996) Interannual climate variability and snowpack in the western United States. J Clim 9:928-948

Clement AC, Seager R, Cane MA, Zebiak SE (1996) An ocean dynamical thermostat. J Clim 9:2190-2196

Coleman JSM, Rogers JC (2003) Ohio River Valley winter moisture conditions associated with the Pacific-North American teleconnection pattern. J Clim 16:969-981

Coleman JSM, Rogers JC (2007) A synoptic climatology of the central United States and associations with Pacific teleconnection pattern frequency. J Clim 20:3485-3497

Cook ER (1985) A time series analysis approach to tree-ring standardization. Dissertation, University of Arizona, Tuscon, USA

Cook ER, Briffa KR, Jones PD (1994) Spatial regression methods in dendroclimatology $-\mathrm{a}$ review and comparison of 2 techniques. Int J Climatol 14:379-402

Cook ER, Kairiukstis LA (1990) Methods of dendrochronology. Kluwer, Dordrecht, The Netherlands

Coulibaly P, Burn DH (2004) Wavelet analysis of variability in annual Canadian streamflows. Water Resour Res 40:W03105

Croci-Maspoli M, Schwierz C, Davies HC (2007) Atmospheric blocking: space-time links to the NAO and PNA. Clim Dyn 29:713-725

Crowley TJ (2000) Causes of climate change over the past 1000 years. Science 289:270-277

D’Arrigo R, Wiles G, Jacoby G, Villalba R (1999) North Pacific sea surface temperatures: past variations inferred from tree rings. Geophys Res Lett 26:2757-2760

D'Arrigo R, Villalba R, Wiles G (2001) Tree-ring estimates of Pacific decadal climate variability. Clim Dyn 18:219-224

D'Arrigo R, Wilson R, Deser C, Wiles G, Cook E, Villalba R, Tudhope A, Cole J, Linsley B (2005) Tropical-North Pacific climate linkages over the past four centuries. J Clim 18:52535265

Davis RE, Benkovic SR (1994) Spatial and temporal variations of the January circumpolar vortex over the Northern-Hemisphere. Int J Climatol 14:415-428

Deser C, Phillips AS, Hurrell JW (2004) Pacific interdecadal climate variability: Linkages between the tropics and the North Pacific during boreal winter since 1900. J Clim 17:3109-3124

Diaz HF, Markgraf V (2000) El Niño and the southern oscillation: multiscale variability and global and regional impacts. Cambridge University Press, Cambridge

Driscoll WW, Wiles GC, D'Arrigo RD, Wilmking M (2005) Divergent tree growth response to recent climatic warming, Lake Clark National Park and Preserve, Alaska. Geophys Res Lett 32:L20703

Fritts HC (1976) Tree rings and climate. Academic Press, London

Eddy J (1977) Climate and the changing Sun. Clim Change 1:173190

Esper J, Frank D, Buntgen U, Verstege A, Luterbacher J (2007) Longterm drought severity variations in Morocco. Geophys Res Lett 34:L17702

Gedalof Z, Smith DJ (2001) Interdecadal climate variability and regime-scale shifts in Pacific North America. Geophys Res Lett 28:1515-1518
Gedalof Z, Mantua NJ, Peterson DL (2002) A multi-century perspective of variability in the Pacific decadal oscillation: new insights from tree rings and coral. Geophys Res Lett 29:L2204

Gershunov A, Barnett TP (1998) Interdecadal modulation of ENSO teleconnections. Bull Am Meteorol Soc 79:2715-2725

Gobena AK, Gan TY (2006) Low-frequency variability in Southwestern Canadian stream flow: links with large-scale climate anomalies. Int J Climatol 26:1843-1869

Graham NE (1994) Decadal-scale climate variability in the tropical and North Pacific during the 1970s and 1980s-observations and model results. Clim Dyn 10:135-162

Graumlich LJ (1993) A 1000-year record of temperature and precipitation in the Sierra Nevada. Quat Res 39:249-255

Graumlich LJ, Pisaric MFJ, Waggoner LA, Littell JS, King JC (2003) Upper Yellowstone River flow and teleconnections with Pacific basin climate variability during the past three centuries. Clim Change 59:245-262

Greig-Smith P (1983) Quantitative plant ecology. University of California Press, Berkeley

Hamlet AF, Mote PW, Clark MP, Lettenmaier DP (2005) Effects of temperature and precipitation variability on snowpack trends in the western United States. J Clim 18:4545-4561

Henderson KG, Robinson PJ (1994) Relationships between the Pacific North-American Teleconnection patterns and precipitation events in the South-Eastern USA. Int $\mathrm{J}$ Climatol 14:307-323

Honda M, Nakamura H (2001) Interannual seesaw between the Aleutian and Icelandic lows. Part II: its significance in the interannual variability over the wintertime Northern Hemisphere. J Clim 14:4512-4529

Honda M, Yamane S, Nakamura H (2005) Impacts of the AleutianIcelandic low seesaw on surface climate during the twentieth century. J Clim 18:2793-2802

Horel JD, Wallace JM (1981) Planetary-scale atmospheric phenomena associated with the southern oscillation. Mon Weather Rev 109:813-829

Hsieh WW, Tang B (2001) Interannual variability of accumulated snow in the Columbia basin, British Columbia. Water Resour Res 37:1753-1759

Jenkins GM, Watts DG (1968) Spectral analysis and its applications. Holden-Day, San Francisco, USA

Jin JM, Miller NL, Sorooshian S, Gao XG (2006) Relationship between atmospheric circulation and snowpack in the western USA. Hydrol Process 20:753-767

Kaplan A, Cane M, Kushnir Y, Clement A, Blumenthal M, Rajagopalan B (1998) Analyses of global sea surface temperature 1856-1991. J Geophys Res 103:18567-18589

Kerr RA (2000) A North Atlantic climate pacemaker for the centuries. Science 288:2113

King JC (2000) North Fork Ridge tree-ring chronology. Data archived at the World Data Center for Paleoclimatology, Boulder, USA

Lau KM, Lee JY, Kim KM, Kang IS (2004) The North Pacific as a regulator of summertime climate over Eurasia and North America. J Clim 17:819-833

Leathers DJ, Palecki MA (1992) The Pacific North-American teleconnection pattern and United-States climate. 29 temporal characteristics and index specification. J Clim 5:707-716

Leathers DJ, Yarnal B, Palecki MA (1991) The Pacific NorthAmerican teleconnection pattern and United-States climate.1. Regional temperature and precipitation associations. J Clim 4:517-528

Linderholm HW, Folland CK, Hurrell JW (2007) Reconstructing Summer North Atlantic Oscillation (SNAO) variability over the last five centuries. Tree Rings in Archaeology, Climatology and Ecology, TRACE 5:6-13 
Linsley BK, Wellington GM, Schrag DP (2000) Decadal sea surface temperature variability in the subtropical South Pacific from 1726 to 1997 AD. Science 290:1145-1148

Luckman BH, Briffa KR, Jones PD, Schweingruber FH (1997) Treering based reconstruction of summer temperatures at the Columbia Icefield, Alberta, Canada, AD 1073-1983. Holocene 7:375-389

Luterbacher J, Xoplaki E, Dietrich D, Rickli R, Jacobeit J, Beck C, Gyalistras D, Schmutz C, Wanner H (2002) Reconstruction of sea level pressure fields over the Eastern North Atlantic and Europe back to 1500 . Clim. Dyn. 18:545-561

MacDonald GM, Case RA (2005) Variations in the Pacific decadal oscillation over the past millennium. Geophys Res Lett 32:L08703

Magnuson JJ, Robertson DM, Benson BJ, Wynne RH, Livingstone DM, Arai T, Assel RA, Barry RG, Card V, Kuusisto E, Granin NG, Prowse TD, Stewart KM, Vuglinski VS (2000) Historical trends in lake and river ice cover in the Northern Hemisphere. Science 289:1743-1746

Mann ME, Cane MA, Zebiak SE, Clement A (2005) Volcanic and solar forcing of the tropical Pacific over the past 1000 years. J Clim 18:447-456

Mantua NJ, Hare SR, Zhang Y, Wallace JM, Francis RC (1997) A Pacific interdecadal climate oscillation with impacts on salmon production. Bull Am Meteorol Soc 78:1069-1079

McCabe GJ (1994) Relationships between atmospheric circulation and snowpack in the Gunnison River Basin Colorado. J Hydrol 157:157-175

McCabe GJ, Fountain AG (1995) Relations between atmospheric circulation and mass-balance at South Cascade Glacier, Washington USA. Arct Alp Res 27:226-233

Michaelsen J (1987) Cross-validation in statistical climate forecast models. J Clim Appl Meteorol 26:1589-1600

Mitchell TD, Carter TR, Jones PD, Hulme M, New M (2004) A comprehensive set of high-resolution grids of monthly climate for Europe and the globe: the observed record (1901-2000) and 16 Scenarios (2001-2100). Working paper 55. Tyne Centre for Climate Change Research, University of East Anglia, Norwich

Moore RD, McKendry IG (1996) Spring snowpack anomaly patterns and winter climatic variability, British Columbia, Canada. Water Resour Res 32:623-632

Overland JE, Adams JM, Bond NA (1999) Decadal variability of the Aleutian low and its relation to high-latitude circulation. J Clim 12:1542-1548

Redmond KT, Koch RW (1991) Surface climate and streamflow variability in the Western United-States and their relationship to large-scale circulation indexes. Water Resour Res 27:2381-2399

Renwick JA, Wallace JM (1996) Relationships between North Pacific wintertime blocking, El Nino, and the PNA pattern. Mon Weather Rev 124:2071-2076

Rogers JC, Coleman JSM (2003) Interactions between the Atlantic multidecadal oscillation, El Nino/La Nina, and the PNA in winter Mississippi valley stream flow. Geophys Res Lett 30:L1518

Romolo L, Prowse TD, Blair D, Bonsal BR, Marsh P, Martz LW (2006a) The synoptic climate controls on hydrology in the upper reaches of the Peace River Basin. Part II: snow ablation. Hydrol Process 20:4113-4129

Romolo L, Prowse TD, Blair D, Bonsal BR, Martz LW (2006b) The synoptic climate controls on hydrology in the upper reaches of the Peace River Basin. Part I: snow accumulation. Hydrol Process 20:4097-4111
Sheridan SC (2003) North American weather-type frequency and teleconnection indices. Int J Climatol 23:27-45

Stuiver M, Braziunas TF (1989) Atmospheric C-14 and century-scale solar oscillations. Nature 338:405-408

Torrence C, Compo GP (1998) A practical guide to wavelet analysis. Bull Am Meteorol Soc 79:61-78

Trenberth KE, Hurrell JW (1994) Decadal atmosphere-ocean variations in the Pacific. Clim Dyn 9:303-319

Trenberth KE, Paolino DA (1980) The Northern Hemisphere sea level pressure data set: trends, errors, and discontinuities. Mon Weather Rev 108:855-872

Trouet V, Taylor AH, Carleton AM, Skinner CN (2006) Fire-climate interactions in forests of the American Pacific coast. Geophys Res Lett 33:L18704

Trouet V, Esper J, Graham NE, Baker A, Scourse JD, Frank DC (2009a) Pervasive positive North Atlantic Oscillation mode dominated the medieval climate anomaly. Science 324:78-80

Trouet V, Taylor AH, Carleton AM, Skinner CN (2009b) Interannual variations in fire weather, fire extent, and synoptic-scale circulation patterns in northern California and Oregon. Theor Appl Climatol 95:349-360

van Oldenborgh GJ, Burgers G (2005) Searching for decadal variations in ENSO precipitation teleconnections. Geophys Res Lett 32:L15701

Verdon DC, Franks SW (2006) Long-term behaviour of ENSO: interactions with the PDO over the past 400 years inferred from paleoclimate records. Geophys Res Lett 33:L06712

Wallace JM, Gutzler DS (1981) Teleconnections in the geopotential height field during the Northern Hemisphere winter. Mon Weather Rev 109:784-812

Westerling AL, Hidalgo HG, Cayan DR, Swetnam TW (2006) Warming and earlier spring increase western US forest wildfire activity. Science 313:940-943

Wiles GC, Darrigo RD, Jacoby GC (1996) Temperature changes along the gulf of Alaska and the Pacific Northwest coast modeled from coastal tree rings. Can J For Res 26:474-481

Wiles GC, Krawiec AC, D'Arrigo RD (2009) A 265-year reconstruction of Lake Erie water levels based on North Pacific tree rings. Geophys Res Lett 36:L05705

Wilson R, Wiles G, D’Arrigo R, Zweck C (2007) Cycles and shifts: 1, 300 years of multi-decadal temperature variability in the Gulf of Alaska. Clim Dyn 28:425-440

Woodhouse CA, Lukas JJ (2006) Multi-century tree-ring reconstructions of Colorado streamflow for water resource planning. Clim Change 78:293-315

Yarnal B, Diaz HF (1986) Relationships between extremes of the southern oscillation and the winter climate of the AngloAmerican Pacific Coast. J Climatol 6:197-219

Yarnal B, Leathers DJ (1988) Relationships between interdecadal and interannual climatic variations and their effect on Pennsylvania climate. Ann Assoc Am Geogr 78:624-641

Yu B, Zwiers FW (2007) The impact of combined ENSO and PDO on the PNA climate: a 1, 000-year climate modeling study. Clim Dyn 29:837-851

Yu B, Shabbar A, Zwiers FW (2007) The enhanced PNA-like climate response to Pacific interannual and decadal variability. J Clim 20:5285-5300

Zhang R, Delworth TL (2007) Impact of the atlantic multidecadal oscillation on North Pacific climate variability. Geophys Res Lett 34:L23708 